Cell Physiol Biochem 1994;4:75

\title{
Contents, Vol. 4, 1994
}

Schwarz, W.

Introductory Remarks

77

Vasilets, L.A.; Schwarz, W.

The Na+/K+ Pump: Structure and Function of the Alpha-Subunit

81

Schmalzing, G.; Gloor, S.

$\mathrm{Na}+/ \mathrm{K}+$-Pump Beta Subunits: Structure and Functions

96

Klaassen, C.H.W.; De Pont, J.J.H.H.M.

Gastric $\mathrm{H}+/ \mathrm{K}+$-ATPase

115

Inesi, G.; Lu, L,; Kirtley, M.E.; Takeyasu, K.

Distinct Structural Identities of Catalytic and

$\mathrm{Ca} 2+$ Binding Domains in the Sarcoplasmic Reticulum

ATPase

135

Penniston, J.T.; Enyedi, A.

Plasma Membrane Ca2+ Pump: Recent Developments

148

Altendorf, K.; Epstein, W. Kdp-ATPase ofEscherichia coli 160 75 